\title{
Research on seismic technology of civil engineering structure based on GIS system
}

\author{
Yu Jingiing ${ }^{1^{*}}$ \\ ${ }^{1}$ Jinan university, Guangzhou, Guangdong, China ,510000
}

\begin{abstract}
The development and application of seismic technology in civil engineering structures is of great significance to extend the service life of buildings and improve the overall quality of buildings, so it is necessary to further strengthen the research on it. Geographic Information System (GIS) is a new subject integrating computer science, informatics, geography and other sciences. Because of its rapid and convenient management of massive data, GIS has been widely used in the fields of resource development, environmental protection, urban planning and construction, disaster monitoring and evaluation, etc. GIS is used to manage and analyze the data, and the damage detection module in the system is used to realize the structural damage identification. And use that special thematic analysis function of GIS to display the data on the map in the form of statistical graph, so that users can find the damage position more directly and clearly.
\end{abstract}

\section{Introduction}

Earthquake is the most serious sudden natural disaster that endangers people's lives and property. In addition to causing personal injury and death, the earthquake also destroyed buildings, interrupted public facilities such as transportation, power supply, water supply, gas supply, oil transportation and communication, and then caused secondary disasters such as water, fire and disease, which brought extremely serious consequences to social life. These public facilities are just as important to human life as arteries, nerves and digestive and respiratory systems in human body, so they are vividly called the lifeline of cities. In the process of civil engineering construction, in order to avoid bean curd residue engineering, the seismic performance of the designed building should be considered [1]. The main purpose of this seismic design is to better control the state of buildings in the event of earthquakes, so that buildings can keep their use functions as much as possible in the event of earthquakes, and reduce the phenomenon of collapse and damage. Seismic treatment of civil engineering buildings is not only to reduce economic losses caused by earthquakes, but also to reduce casualties during earthquakes.

Geographic Information System (GIS) is a relatively mature computer system developed in recent ten years, which is being widely used by various departments to establish practical systems [2-3]. It can conveniently collect, analyze, manage and output spatial data. It has the ability of regional analysis, multi-factor analysis and dynamic prediction, and is easy to combine with analysis model. Applying GIS to urban earthquake disaster prevention, we can establish practical analysis model and make loss assessment and emergency plan in time by controlling spatial geographic information, lifeline engi- neering, buildings and structures and other disaster relief facilities, thus improving disaster relief efficiency and saving precious time for earthquake relief.

\section{Several factors affecting seismic resistance of structures in civil engineering}

\subsection{Construction site of the project}

When an earthquake occurs, different construction sites suffer different degrees of earthquake damage, so it is particularly important to choose their construction sites in the process of civil engineering construction, and this is also an important factor that directly affects the seismic effect of this engineering construction. A good and wide site can not only effectively reduce the earthquake feeling, but also facilitate the construction unit to build the foundation better [4]. If there is no strict quality guarantee for the foundation, the whole building will be unable to achieve the anti-seismic effect required by the design when an earthquake occurs. Therefore, when selecting the engineering site, the site with hard address or medium hard land with dense and uniform geology should be selected as much as possible, and the sites such as landslide and inclination should be avoided as much as possible.

\subsection{Building structural system}

In order to ensure the safety of buildings, it is necessary to choose a suitable building structure system, which is closely related to each other. First of all, when carrying out seismic design, the building structure has a certain

*zxbtianyi@vip.qq.com 
degree of redundancy for correctly handling the relationship between the whole and the part, and the whole building cannot be affected by individual buildings. If the part of the building is damaged, it is necessary to ensure that the seismic performance of the structure is not affected.

\subsection{Seismic prevention}

According to the current construction situation of civil engineering in China, the seismic performance of buildings is relatively poor, which is mainly because the parameters are not strictly set in the construction process, such as the bearing capacity of beams and columns, which do not meet the relevant seismic standards, resulting in huge economic losses and casualties once an earthquake occurs. Therefore, at present, it is necessary to change the structural design method and adopt the elastic design method to ensure that the building will not be damaged in the event of a low-grade earthquake, and that the building can be kept intact in the event of a moderate earthquake through repair, and that the building will not collapse in the event of a large earthquake [5-6], so that the loss caused by the earthquake can be controlled within the minimum range.

\section{Function of seismic design in civil engineering}

\subsection{Improve the seismic performance level of civil engineering}

First of all, when we do the site selection design, we need to do a good job of research and survey for the selection of the ground in civil engineering, and we need to study all aspects of the stability, firmness and hardness of the ground. Starting from the foundation, do a good job of earthquake prevention performance of civil engineering effectively. Doing a good job in seismic design of civil engineering can effectively improve its seismic performance, which is conducive to the safety of housing construction and effectively protect the life and property rights of its users and residents.

\subsection{Improve the stiffness level of civil engineering}

At the present stage, we find that many houses often collapse immediately when earthquakes come, which brings many hidden dangers to the people of our country. One of the main reasons is that the rigidity of civil engineering is not high when it is designed and built, so it is often difficult to withstand the influence of its moving force when it reacts violently to geological activities [7]. Therefore, if we effectively increase the seismic design work in civil engineering design, then we can effectively improve the stiffness of the building.

\subsection{Reduce the impact of earthquake disasters on buildings}

At present, geological disasters have a very high degree of damage to civil engineering in China. At present, all the measures we have taken are simply to add an isolation seismic layer, in an attempt to effectively reduce the impact of earthquake disasters on buildings only through this isolation layer. Obviously, this is very unscientific. Therefore, if we effectively increase the work of seismic design in civil engineering design, we can effectively reduce the impact of earthquake disasters on buildings.

\section{Seismic technology of civil engineering structure based on GIS system}

\subsection{Spatial data acquisition and processing}

The ways to obtain geospatial data are: hand-held tracking digitizer, automatic scanning, remote sensing data input and electronic graphic files, etc. Urban planning and engineering design drawings are important sources for civil engineering GIS to obtain geospatial data [8]. The appearance of scanning technology undoubtedly provides a powerful tool for spatial data entry. The common map scanning process is shown in Figure 1. Because the scanning format of the scanner is generally smaller than that of the map, the large paper map needs to be scanned in blocks first, then the adjacent maps are connected, and each primitive is vectorized to generate a vector map which is convenient for editing and processing, and finally becomes a complete vector electronic map, which can be edited and processed such as modification, annotation and calculation.

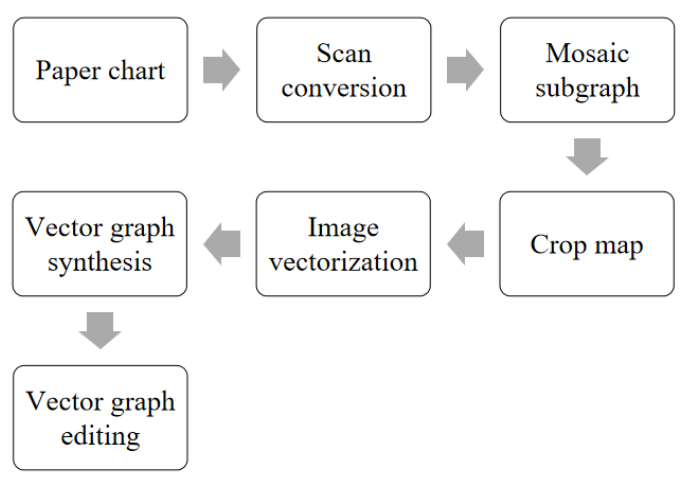

Fig. 1. Scan map processing flow chart

The construction progress information is involved in the calculation of construction period and the optimization of construction process of each sub-project. The total project progress is composed of the progress of subdivisional work, and the progress of subdivisional work is composed of the progress of unit project. Engineering and technical personnel of subdivisional work enter the progress value of unit work according to the actual construction progress, which provides basic data for time limit calculation and construction process optimization of subdivisional work on the one hand, and summarizes it 
into the total progress on the other hand, which is convenient for the highest-level managers to make overall arrangement, control progress and optimize resource allocation.

\subsection{Spatial database of urban earthquake resistance and disaster prevention}

As a complete urban earthquake prevention system, it should have the following parts [9]: (1) urban earthquake prevention spatial database; (2) Urban earthquake information analysis module (3) Urban earthquake damage prediction module; (4) Urban earthquake shock simulation module; (5) Urban earthquake prevention and disaster prevention countermeasure module. The following is a brief introduction to the logic diagram of the urban earthquake prevention system. Figure 2 below:

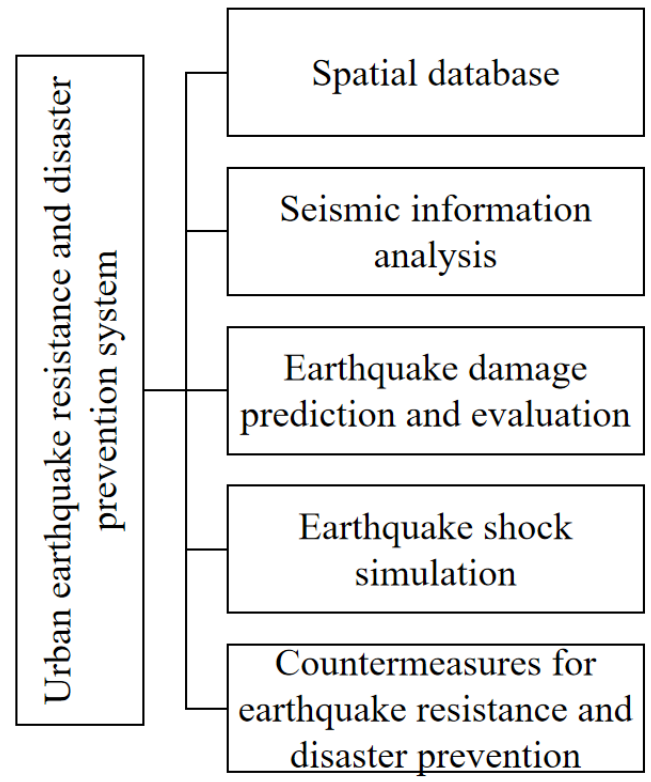

Fig. 2. Logic diagram of earthquake resistance and disaster prevention system

The construction of spatial database is the foundation of every work, and its construction will directly affect the operation of other modules. The collection and input process of GIS data takes up most of the time of the whole system development, and the future system maintenance is mainly for system data maintenance.

It is generally believed that the establishment of database will account for $50 \% \sim 70 \%$ of the project cost, which makes some departments trying to carry out GIS application projects discouraged. This "bottleneck" problem has always been a difficult problem for building a well-running system. Under the existing resources and technical level, the following databases can be built [5]:

(1) Data sharing. For the existing resources, the existing data of other departments can be shared through the database management system on the network.

(2) Transformation of existing data. Some existing data can't be shared, but can be stored in the database through the conversion of data format. ARC/INFO provides many types of format conversion, such as DXF,
IGES, TIGER, ERDAS, etc., which will undoubtedly greatly reduce the workload of database construction.

(3) Multi-mode acquisition. For the highly specialized seismic information data, it is often impossible to obtain them from other departments, so they have to be input by the database builders themselves. There are various ways to do this, such as scanning and digitization.

\subsection{Mechanical analysis}

Rocks are mainly natural bodies formed by the aggregation of mineral crystals and cementitious materials according to certain rules under geological action. Within a certain load range, rock can be regarded as elastic body, and the stress-strain curve of rock is shown in Figure 3.

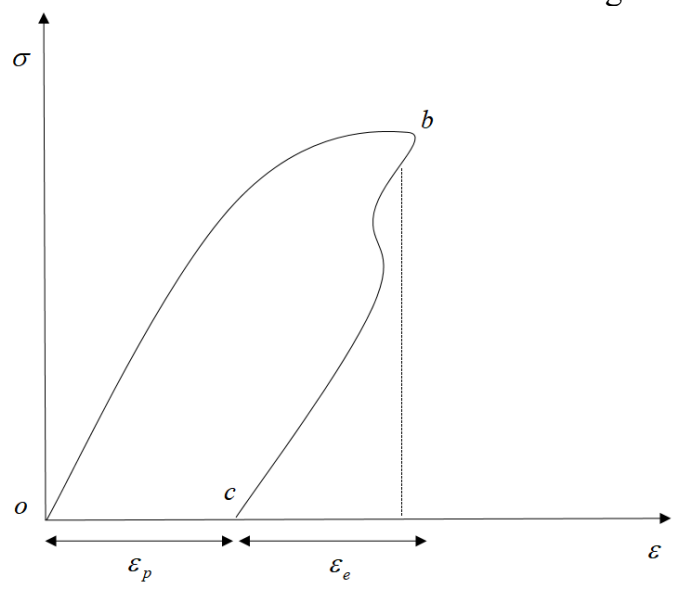

Fig. 3. Stress-strain curve of rock

The stress-strain curve is divided into straight line segment $o a$ and curve segment $a b$. In $o a$ section, the relationship between stress and strain of rock almost keeps linear proportional relationship and obeys Hooke's law. Therefore, in $o a$ section, the deformation of rock can be regarded as elastic deformation. At the same time, the deformation of rock occurs instantaneously with loading. When the load is removed, the deformation can be completely recovered immediately. With the increase of stress, the strain does not keep a linear proportional relationship with stress, and the corresponding stress-strain curve becomes a certain curve, and with the increase of stress, the curve tends to approach a horizontal straight line.

If the rock specimen is unloaded step by step after loading to point $b$, it will be found that the unloading curve deviates from the loading curve, and when it is completely unloaded, the unloading curve does not return to the origin $O$, but reaches the point $C$ of the horizontal axis. At this time, the deformation of rock can be divided into two parts: One is the restored elastic deformation $\varepsilon_{e}$, and the other is the unrecoverable plastic deformation $\varepsilon_{p}$. This means that rocks are not only elastic, but also plastic. 
A natural rock mass, macroscopically speaking, is composed of rock blocks which are cut by joints or fissures and arranged and engaged with each other.

There are obvious geological relics in rock mass, such as false integration, unconformity, fold, fault, joint, cleavage and so on. They are generally called joints in rock mechanics. Because of the existence of joints, the medium is discontinuous. Therefore, these interfaces are also called discontinuities or structural planes. It causes discontinuity and anisotropy of rock mass, and also reflects the characteristics of regional geological structure and natural stress field.

\subsection{Seismic performance analysis of structures}

For this type of high-rise building structure with large chassis, the stress of the structure under earthquake action is complex, and there are many factors that affect the response of the structure under earthquake action. In this section, the elastic time history analysis of the structure is mainly carried out from several aspects such as the number of floors and stiffness of the chassis, and the influence of these factors on the seismic performance of the structure is considered [10]. According to the seismic waves selected above, the elastic time history analysis of the structure under frequent earthquakes is carried out. It can be seen from the analysis that the first vibration mode of the structure is Y-direction translation, and the structure is unfavorable under the action of seismic wave KAR-3. In this section, the seismic response results of Ydirection KAR.3 seismic waves are selected for analysis.

For this type of complex high-rise structure, the large chassis generally has 2 6 floors, and the height of the tower above the chassis varies greatly. Different chassis heights inevitably make different structures have different seismic responses. In this section, under the condition of keeping the height of the model unchanged, the influence of the number of floors of the chassis on the seismic response of this type of high-rise structure is studied by changing the number of floors of the chassis. Adjust the number of chassis floors to three, four, five and six respectively.

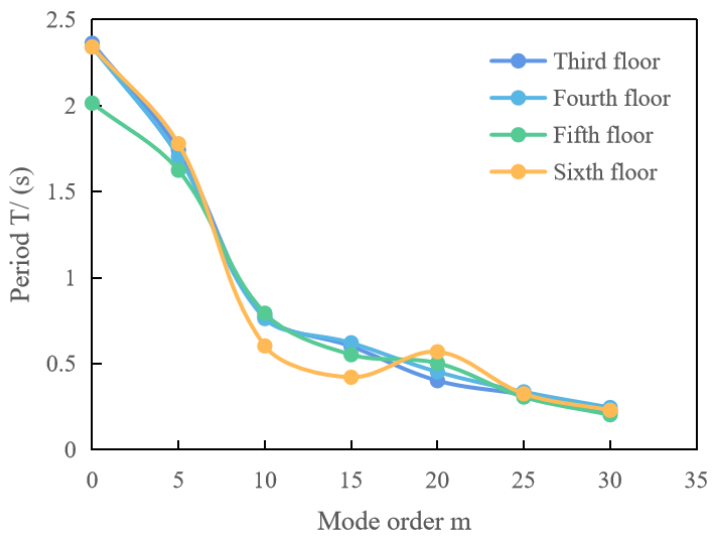

Fig. 4. Period of structure with different chassis layers

It can be seen from the above figure 4 that the number of chassis layers has obvious influence on the low-order modes of the structure, especially the first three modes, and the structure period decreases with the increase of chassis layers; for the high-order modes, the change of structure period is irregular, but the change range is small, indicating that the number of chassis layers has great influence on the low-order modes of the structure, but little influence on the high-order modes. When the number of floors of the chassis increases from three to six, the first translational period of the structure decreases by $9.8 \%$, the second translational period decreases by $7.5 \%$, the first torsional period increases and decreases by about $15.3 \%$, and the ratio of the first torsional period to the first translational period decreases from 0.89 to 0.65 , which shows that with the increase of the number of floors of the chassis, the first torsional period of the structure changes more than the first translational period, and the period ratio decreases.

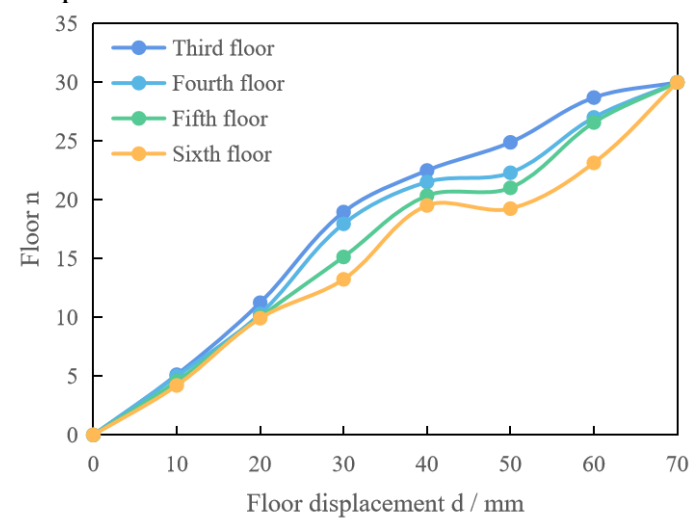

Fig. 5. Floor displacement diagram of different chassis floors

With the increase of the number of floors of the chassis, the floor displacement and the maximum inter-story displacement of the structure obviously increase, and the influence on the superstructure is greater than that on the lower part (Figure 5). With the increase of the number of floors of the chassis, the more the upper part of the structure, the greater the change range of the displacement of the structural floor; However, with the increase of the floor height, the displacement of structural floor increases at first and then decreases. Below 20 floors, the increase amplitude of inter-story displacement increases with the increase of floors, and after more than 20 floors, the increase amplitude decreases with the increase of floors. The lateral force resistant members at the bottom floor of the big chassis should be properly strengthened, and measures such as enlarging the cross section or improving the concrete strength grade of the lateral force resistant members and densifying the stirrup of the frame column can be taken. At the same time, the relative stiffness between the chassis and the tower should be adjusted after increasing the number of floors of the chassis to make them relatively balanced, so as to prevent the excessive stiffness of the chassis from increasing the earthquake action.

\section{Conclusion}

The design of seismic performance is very important in civil engineering structural design, so it is necessary to integrate various factors in the design of seismic performance to improve the seismic performance of the struc- 
ture. In this paper, GIS is used to visually display the image and text information management function, especially the powerful spatial analysis function, which provides a real basis for the evaluation of seismic resistance of urban buildings. Compared with the upper structure, the stiffness of the lower chassis of the complex high-rise structure with large chassis changes greatly, resulting in uneven vertical stiffness distribution of the structure. The floor shear force and inter-story displacement angle suddenly change at the top of the chassis or two floors above the chassis. Therefore, in structural design, structural measures should be strengthened at the top of the chassis and above three floors, so that the overall stiffness of the structure can be coordinated at the top of the large chassis to resist the torsional effect, so as to improve the ductility of the structure under strong earthquakes.

\section{References}

1. Hua X. Model study of civil engineering structure damage identification system based on modern intelligent algorithm[J]. Revista de la Facultad de Ingenieria, 2017, 32(15):196-201.

2. Zhi-Xiong L, Wen-Ping Z, Bin Z. Research on performance detection system and damage identification method based on civil engineering structure $[\mathrm{J}]$. Acta Technica CSAV (Ceskoslovensk Akademie Ved), 2017, 62(1):201-213.

3. Zhang X. Energy-Saving Design of Civil Engineering Buildings Based on FPGA and Embedded System[J]. Microprocessors and Microsystems, 2021, 83(1):103970.

4. Huang W, Ren J, Yang T, et al. Research on urban modern architectural art based on artificial intelligence and GIS image recognition system $[\mathrm{J}]$. Arabian Journal of Geosciences, 2021, 14(10):1-13.

5. Xiang Shiyao, Chen Tingting and Zhang Tao. Design for UAV aerial survey data management system of highway based on GIS[J]. Shandong Communications Technology, 2018, 000(006):71-72,82.

6. Xu Tengteng and $\mathrm{Yu}$ Xiuli. Design of Urban Environmental Emergency Management System Based on GIS $[J]$. Computer and information technology, 2019, 027(003):59-62.

7. Guan G, Qu Y. Design and Optimization for Ship Structure Based on Knowledge-Based Engineering $[\mathrm{J}]$. Journal of Ship Production and Design, 2017, 34(3):191-201.

8. Lei N N H, Zhang N N Y, Hu N N Y, et al. Model test and discrete element method simulation of shield tunneling face stability in transparent clay[J]. The frontier of structure and civil engineering, 2021, 15(1):147-166.

9. Guan G, Yang Q. Design and Optimization for Ship Structure Based on Knowledge-Based Engineering $[J]$. Journal of Ship Production and Design, 2018, 34(3):191-201.

10. Zhang B, Ye Y W, Shen X Z, et al. Design and implementation of levee project information manage- ment system based on Web GIS[J]. Royal Society

Open Science, 2018, 5(7):180625. 